\title{
Effects of Different Concentrations of Bleaching Agent on the Shear Bond of Restorative Materials - An In Vitro Study
}

Srinivasan $\mathrm{K}^{1}$, Chitra $\mathrm{S}^{2}$

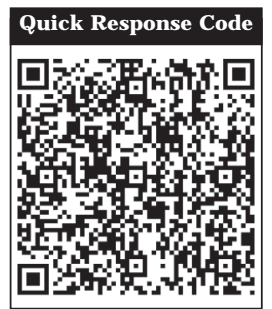

doi : 10.5866/2015.7.10105

${ }^{1}$ Senior Lecturer

Department of Pedodontics And Preventive Dentistry, Adhiparasakthi Dental College And Hospital,

Melmuruvathur (T.N. State).

${ }^{2}$ Associate Professor

Department Of Anaesthesia,

Chirstian Medical College,

Vellore (T.N. State).

\section{Article Info:}

Received: April 10, 2015

Review Completed: May 9, 2015

Accepted: J une 8, 2015

Available Online: April, 2015 (www.nacd.in)

(C) NAD, 2015 - All rights reserved

\section{Email for correspondence:}

skskskpedo@gmail.com

\begin{abstract}
:
BACKGROUND: Bleaching methods had been developed and peroxide compounds at different concentrations are used for tooth whitening procedures.
\end{abstract}

AIM AND OBJ ECTIVE: The aim of the present laboratory study was to evaluate the effect of bleaching with carbamide peroxide agents at concentrations 10 and $21 \%$ on the shear bond strength of Nano Composites and Nano hybrid Composite restorative materials.

MATERIAL AND METHODS: 60 non carious premolars extracted for orthodontic reasons were selected for the study. The restorative materials were filled in a twolayer increment technique, each layer being light cured separately for 40 s using light cure unit. F or shear bond strength evaluation, samples of both were subdivided into control group (stored in artificial saliva), Experimental groups bleached with $10 \%$ carbamide peroxide and those bleached with $21 \%$ carbamide peroxide. Fol lowing 2 weeks of bleaching treatment, the shear bond test was performed using Instron universal testing machine.

STATISTICAL ANALYSIS: One way Analysis of Variance (ANOVA) was used for multiple group comparisons followed by Tukey's test for pair wise comparison.

RESULTS: Bleaching with carbamide Peroxide at concentrations 10 and $21 \%$ caused reduction in bond strength of composite restorative materials.

CONCLUSION: It can be deduced that bleaching caused reduction in bond strength of composite restorative materials.

Key words: Aesthetics, Beauty, bleaching, Carbamide peroxide, Developmental defects, Discoloured enamel, Micro hardness.

\section{INTRODUCTION:}

Esthetic dentistry is one among the most dynamic areas of contemporary clinical dentistry. Widespread interest in esthetic dentistry among members of the profession, the dental industry, and the public had a marked effect on general dental practice. ${ }^{1}$ Patients' increased awareness of esthetic outcomes and their desire to look better and to feel better about themselves have led to enormous demands on dentists to perform esthetic procedures. 
Tooth discoloration is becoming a greater concern as more emphasis is placed on esthetics. Bleaching systems have been received by the public as a more conservative and economical method of improving the appearance of the Dentition. ${ }^{1}$ Dentist's ability to fulfil patients' expectations is directly related to their knowledge and clinical skills in this area. ${ }^{2}$

Bleaching methods had been developed and peroxide compounds at different concentrations are used for tooth whitening procedures. Peroxidecontaining vital tooth whiteners are classified into three categories, according to application mode and peroxide concentration. Oxidizing agents for professional use only contain high concentrations of Carbamide Peroxide (35-37\%) and Hydrogen Peroxide (30-35\%) solutions, while patient-applied tooth whiteners for at-home bleaching, containing up to $20 \%$ Carbamide Peroxide and $10 \%$ Hydrogen Peroxide, are dispensed, and monitored by dentist. ${ }^{3}$

The purposes of the present study were to evaluate the effects of bleaching agents on dental restorative materials-the Nano Compositeand Nano Hybrid Composite.

METHODS: The present study was conducted in the Department of Pedodontics and Preventive Dentistry, Rajah Muthiah Dental College and Hospital, Annamalai University in association with Department of Manufacturing Engineering, faculty of Engineering and Technology, Annamalai University.

Restorative materials used were Nano Composite $\{$ Te-E conom plus, I voclar Vivadent (RO353) $\}$ and Nanohybrid Composite TTetric N Cream, I voclar Vivadent (P87103)\}.Bleaching agent used were Carbamide peroxide 10\% \{Opalescence\} and Carbamide peroxide $21 \%$ (d-tech) ${ }^{4}$

\section{Sampling for Shear bond strength evaluation}

60 non carious premolars extracted for orthodontic reasons were used for this study. Each tooth was embedded in acrylic resin exposing the buccal surface. Then the outer enamel surface was ground flat with the help of 320 grit sand paper to obtain a flat dentinal surface. The dentin surface of each specimen was etched with $35 \%$ phosphoric acid for 15 seconds, washed and blotted dry. Two coats of single bond was applied over each of the specimens and light cured for 20 seconds. Cylindrical Teflon mold measuring $2 \mathrm{~mm}$ in diameter and $4 \mathrm{~mm}$ in height was used to build the Nano Composite and Nano Hybrid Composite cylinders on the dentinal surface. The restorative materials were filled in a two layer increment technique, each layer being light cured separately for 40 seconds using light cure unit. Thirty samples of each restorative material were subdivided into 3 groups of ten each. ${ }^{4}$

The specimens for Shear bond strength evaluation assigned for the bleaching regimes are given in Table 1- Nano Composite group and Table2Nano Hybrid Composite group.

The bleaching protocol in the present study was designed to simulate treatment of teeth under cycling conditions of bleach and saliva exposure which is encountered under in situ conditions (Kudalkar and Damle, 1997). The control test specimens of restorative materials were stored in artificial saliva throughout and the experimental test specimens while they were not being "bleached" in order to simulate oral conditions as closely as possible.

Artificial saliva comprised of Sodium chloride $(\mathrm{NaCl}) 0.4 \mathrm{~g}$, Potassium chloride $(\mathrm{KCl}) 0.4$ Calcium chloride $\left(\mathrm{CaCl}_{2} \cdot \mathrm{H}_{2} \mathrm{O}\right) 0.795 \mathrm{~g}$, Sodium-dihydrogen Phosphate $\left(\mathrm{NaH}_{2} \mathrm{PO}_{4} \cdot \mathrm{H}_{2} \mathrm{O}\right) 0.69 \mathrm{~g}$, Sodium sulfide $\left(\mathrm{Na}_{2} \mathrm{~S} .9 \mathrm{H}_{2} \mathrm{O}\right) 0.005 \mathrm{~g}$ and distilled water $1000 \mathrm{ml}$. The pH was adjusted to 7 (Attin, 1996). ${ }^{4}$

\section{Bleaching regime}

The test specimens of the experimental group were bleached with Carbamide peroxide gels at $10 \%$ or $21 \%$, for 8 hours daily for a period of 2 weeks.

For Shear bond strength samples, the bleaching gels were applied at the bonded interfaces. After treatment with Carbamide peroxide gel, the test specimens were abundantly washed under running water, dried with absorbent paper, and immersed in artificial saliva for remaining 16 hours of the day.

The test specimens from the control group were kept in artificial saliva all the time, with the saliva being changed daily. ${ }^{4}$ 


\section{Study of Shear bond strength}

After two weeks of treatment, experimental and the control specimens were analyzed in a Micro hardness meter.

The Shear bond test were performed using Universal testing machine at a cross head speed of $0.5 \mathrm{~mm} \mathrm{~min}^{-1}{ }^{1}$ in a compression mode using a blade parallel to the dentinal surfaces as the shearing element and the readings were noted.

Measurements were expressed as mean \pm standard deviation and were compared between two groups by student's t test. One-way ANOVA was used for multiple group comparisons followed by Tukey's test for pair wise comparison. $P$ value less than 0.05 was considered for statistical significance.

\section{RESULTS:}

The results and observations of shear bond strength are summarized as follows:

\section{SHEAR BOND STRENGTH EVALUATION}

The Shear bond strength the specimen were calculated using the formulae

FORMULAE : area $=ð / 4 \times r^{2}=ð / 4 \times 4^{2}=12.56 \mathrm{~mm}^{2}$

Where, $\mathrm{R}=$ radius, Stress=load/area.

The values obtained were expressed in Megapascal (Mpa).

The Shear bond strength values have been expressed as mean and standard devation. $2 \times 3$ ANOVA test were used to compare the Shear bond strength by material and group wise. If the groups were significant, Tukey's multiple comparison tests were applied to know which of the group differs. Level of significance has been fixed as $5 \%(0.05)$.

Comparision of Shear Bond Strength between Nanocomposite and Nanohybrid Composite was done which was indicated in Table 3. The Shear bond strength of Nano Composite and Nanohybrid Composite were reduced when it was treated with $10 \%$ and $21 \%$ bleaching agent. The Shear bond strength of Nanohybrid Composite was better when compared to Nanocomposite. To compare the two materials and the role of bleaching agents, $2 \times 3$
ANOVA test has been applied. 2×3 ANOVA test results are shown in Table 4, Graph 1.

\section{Material comparison:}

The significant ' $p$ ' value of the material comparison infers that the two materials are statistically different. In general the hybrid material is better than the Nano Composite. When the teeth were treated by $\mathrm{N}$ ano Composite material and $21 \%$ bleaching agent the Shear bond strength were reduced compared to the $\mathrm{N}$ ano composite al one and Nano Composite with $10 \%$ bleaching agent. When the teeth were treated by Nano hybrid material and $21 \%$ bleaching agent the Shear bond strength were reduced compared to the Nano hybrid material al one and $\mathrm{N}$ ano hybrid material with $10 \%$ bleaching agent (Table 5). In general the Shear bond strength of Nano hybrid material was better than the Nano Composite.

\section{DISCUSSION:}

Tooth whitening has a long history and has evolved into one of the most popular aesthetic dental treatments available. From "chew sticks" made from twigs dating back to 3000 B.C. and the ancient Romans' discovery that Ammonia in urine could serve as a bleaching agent to today's use of various forms of peroxide to safely whiten teeth, the quest for "pearly whites" threads throughout the history of oral health. In the 1800s, the discovery of fluoride's teeth protecting capabilities allowed for new oral hygiene opportunities. ${ }^{5}$

The aim of the present laboratory study was to evaluate the effect of bleaching with Carbamide Peroxide agents at concentrations $10 \%$ and $21 \%$ on the Shear bond strength of Nano composites and Nano hybrid composite restorative materials.

The importance of the present study were that after eruption of the tooth, aging, pulp necrosis, and iatrogenesis are the main causes of intrinsic discoloration. Coffee, tea, red wine, carrots, oranges, and tobacco give rise to extrinsic stain (Khin, 2000). Exposure to high levels of fluoride, tetracycline administration, inherited developmental disorders, and trauma to the developing tooth may result in pre - eruptive discoloration. Bleaching is a 
conservative treatment alternative for discolored teeth. $^{4}$

Since enamel and dentin are porous tissues, the scientific basis for bleaching vital teeth is sound (Bastinget al., 2003). Clinicians all over the world had incorporated the vital bleaching into their profession and oxygenating agents like carbamide peroxide or Hydrogen peroxideare used for effective bleaching (Garcia-Godoyet al., 2002). ${ }^{4}$

A $10 \%$ Carbamide peroxide bleaching agent is the most commonly used at-home bl eaching product.
A range of concentrations of Carbamide peroxide available to the dental professional include 15, 20, 22 and 30\% solutions (K hin, 2000). It had been reported that whitening of teeth can be achieved faster with higher concentrations compared with the results for lower concentrations of Carbamide peroxide (White et al., 2003). The bleaching protocol in the present study was designed to simulate treatment of teeth under cycling conditions of bleach and saliva exposure which is encountered under in situ conditions (Kudalkar and Damle., 1997). The control test specimens of restorative materials were

Table 1: Nano Composite group

\begin{tabular}{lc} 
Group & Shear bond strength \\
Control & $\mathrm{P} 1$ (10 Samples) \\
\hline $10 \%$ Carbamide Peroxide & $\mathrm{P} 2(10$ Samples $)$ \\
\hline $21 \%$ Carbamide Peroxide & $\mathrm{P} 3(10$ Samples $)$ \\
\hline
\end{tabular}

Table2: Nano Hybrid Composite group

\begin{tabular}{lc} 
Group & Shear bond strength \\
Control & P4(10 Samples) \\
\hline $10 \%$ Carbamide Peroxide & P5(10 Samples) \\
\hline $21 \%$ Carbamide Peroxide & P6(10 Samples) \\
\hline
\end{tabular}

Table 3: Comparision of shear bond strength between nanocomposite and nanohybrid composite

\begin{tabular}{clcccc} 
S.No. & MATERIAL & GROUP & RANGE $(\mathbf{M p a})$ & MEAN (Mpa) & SD \\
\hline 1. & NANO & T1 & $7.96-9.55$ & 8.67 & 0.58 \\
\hline & COMPOSITE & T2 & $7.16-9.55$ & 7.95 & 0.99 \\
\hline & & T3 & $6.36-7.96$ & 7.16 & 0.65 \\
\hline 2. & NANOHYBRID & T4 & $9.55-11.14$ & 10.5 & 0.62 \\
\hline & COMPOSITE & T5 & $7.96-10.35$ & 9.39 & 0.90 \\
\hline & & T6 & $7.16-9.55$ & 8.51 & 0.755 \\
\hline
\end{tabular}

Table 4: ANOVA Test results

\begin{tabular}{clcc} 
No. & SOURCE & F-VALUE & p-VALUE \\
\hline 1 & Material & 60.31 & $\varangle 0.001$ \\
\hline 2 & Group & 26.04 & $\varangle 0.001$ \\
\hline 3 & Material and group & 0.558 & 0.576 \\
\hline
\end{tabular}

One way ANOVA; $\mathrm{P}<0.001$, Significant (S); $\mathrm{P}>0.05$, not significant (NS). 
Table 5: TUKEY'S HONESTLY-SIGNIFICANT-DIFFERENCE TEST

\begin{tabular}{clcc} 
Sample & Material and Group & Mean Difference & P-Value \\
\hline 1 & NANOCOMPOSITE (T1) - NANOCOMPOSITE (T2) & 0.716 & 0.311 (NS) \\
\hline 2 & NANOCOMPOSITE (T1) - NANOCOMPOSITE (T3) & 1.513 & 0.001 (S) \\
\hline 3 & NANOCOMPOSITE (T1) - NANOHYBRID (T4) & -1.833 & 0.000 (S) \\
\hline 4 & NANOCOMPOSITE (T1) - NANOHYBRID (T5) & -0.718 & 0.308 (NS) \\
\hline 5 & NANOCOMPOSITE (T1) - NANOHYBRID (T6) & 0.159 & 0.997 (NS) \\
\hline 6 & NANOCOMPOSITE (T2) - NANOCOMPOSITE (T3) & 0.797 & 0.204 (NS) \\
\hline 7 & NANOCOMPOSITE (T2) - NANONHYBRID (T4) & -2.549 & 0.000 (S) \\
\hline 8 & NANOCOMPOSITE (T2) - NANOHYBRID (T5) & -1.434 & 0.001 (S) \\
\hline 9 & NANOCOMPOSITE (T2) - NANOHYBRID (T6) & -0.557 & 0.588 (NS) \\
\hline 10 & NANOCOMPOSITE (T3) - NANOHYBRID (T4) & -3.346 & 0.000 (S) \\
\hline 11 & NANOCOMPOSITE (T3) - NANOHYBRID (T5) & -2.231 & 0.000 (S) \\
\hline 12 & NANOCOMPOSITE (T3) - NANOHYBRID (T6) & -1.354 & 0.003 (S) \\
\hline 13 & NANOHYBRID (T4) - NANOHYBRID (T5) & 1.115 & 0.023 (S) \\
\hline 14 & NANOHYBRID (T4) - NANOHYBRID (T6) & 1.992 & 0.000 (S) \\
\hline 15 & NANOHYBRID (T5) - NANOHYBRID (T6) & 0.877 & 0.127 (NS) \\
\hline
\end{tabular}

One way ANOVA; $\mathrm{P}<0.001$, Significant (S); $\mathrm{P}>0.05$, not significant (NS).

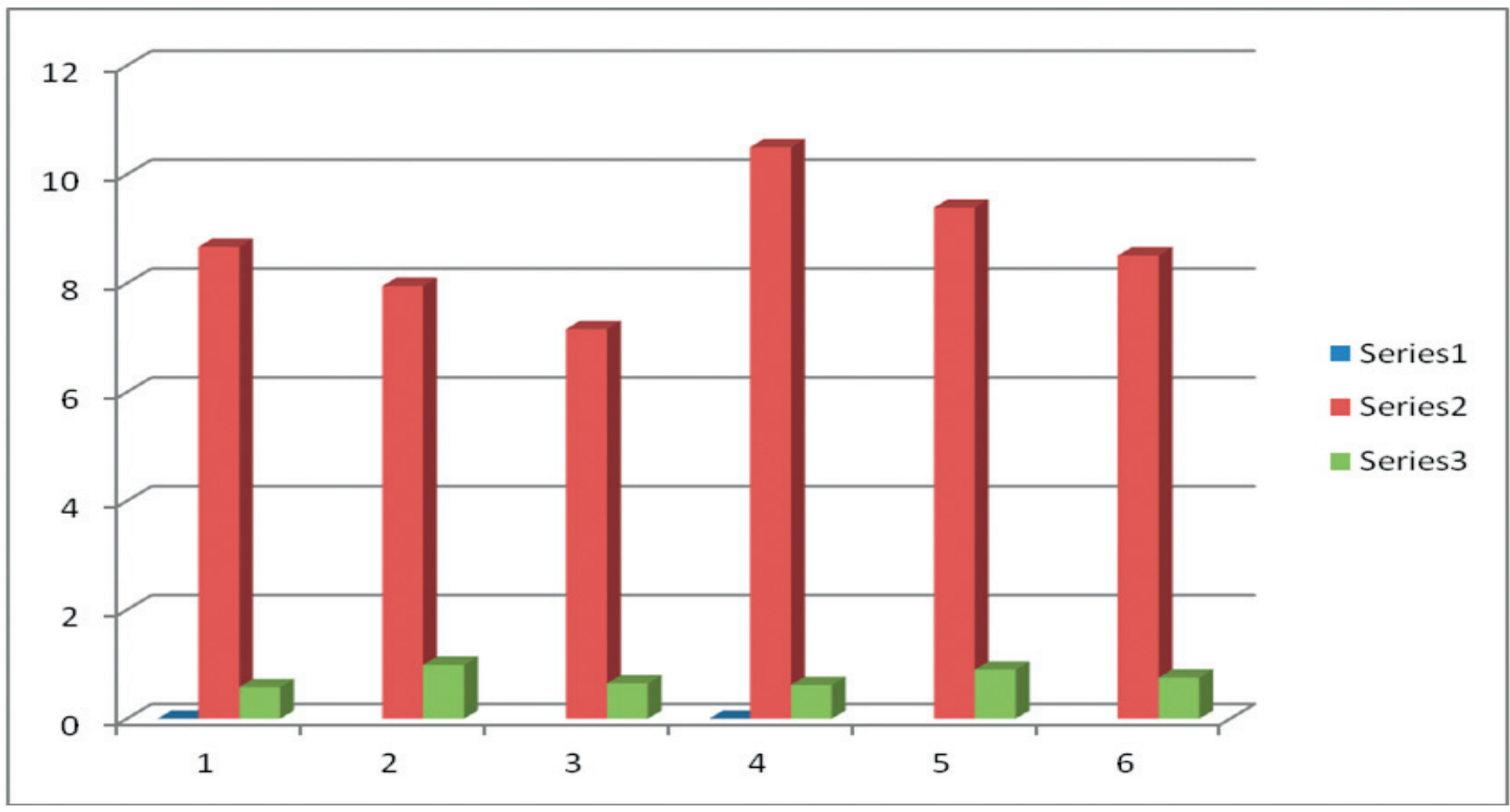

Graph 1: Comparison of Shear bond strength between Nano-Composite and Nano-Hybrid Composite. Series 1- Control group; Series 2-Bleached with 10 \% Carbamide Peroxide; Series 3-Bleached with 21 \% Carbamide Peroxide. 
stored in artificial saliva throughout and the experimental test specimens while they were not being "bleached" in order to simulate oral conditions as closely as possible. ${ }^{4}$

Carbamide peroxide is an organic white crystalline compound composed of Urea and Hydrogen Peroxide. Carbamide peroxide breaks down in the mouth to form Hydrogen Peroxide. The bleaching gel typically contains between $10 \%$ and $44 \%$ Carbamide Peroxide, which is roughly equivalent to a $3 \%$ to $16 \%$ Hydrogen Peroxide concentration. It is supplied as a gel by adding thickening agents like Carbopol, Glycerine, and Glycol etc., to increase its viscosity and prolong its contact with the tooth structure. It is more stable than $\mathrm{H}_{2} \mathrm{O}_{2}$ having a shelf life of up to 2 years. Its bleaching action is similar to $\mathrm{H}_{2} \mathrm{O}_{2}$ but it is safer than the latter. Hence it is currently the most popular bleaching agent at home vital bleaching procedures. ${ }^{5}$

Shear stress is considered to be more representative of the clinical situation. Bond strength is the force per unit area that is required to break a bonded assembly with failure occurring in or near the adhesive/ adherend interface. For Shear bond strength evaluation, a total of 60 non carious premolars extracted due to orthodontic reasons were selected and stored in distilled water before and during the study period, since the distilled water does not affect the dentin permeability and bond strength compared to saline. The buccal surfaces of all the 60 teeth were considered in this study, because this surface allowed the shearing force to be exactly perpendicular to the bonded specimen (Shinohara, 2004).The dentin surface was etched with $35 \%$ Phosphoric acid for 15 seconds. The single bond multi-purpose etchant is a versatile system which is recommended for bonding all classes of restorations. "Single Bond", a fifth generation (type 2) adhesive, was used having both primer and adhesive in one bottle. The main reasons to use an adhesive were to facilitate the penetration of Composite into the etched dentin surface to provide a better bond to tooth structure. Single bond adhesive were found to provide up to $97 \%$ retention rate. Few studies have reported that Carbamide peroxide does not interfere in the adhesion of composite resin with dentin. The reaction of Carbamide peroxide is immediate, and it was probable that the residues of hydrogen peroxide leach rapidly. Furthermore, dentin is a porous substrate, and the peroxide residues of Carbamide peroxide may release the oxygen more easily to the dentin tubules than to enamel.

When the tooth weretreated by Nano Composite material and $21 \%$ bleaching agent the Shear bond strength were reduced compared to the Nano Composite alone and Nano Composite with 10\% bleaching agent. When the tooth were treated by Nano Hybrid material and $21 \%$ bleaching agent the Shear bond strength were reduced compared to the $\mathrm{N}$ ano Hybrid material al one and $\mathrm{N}$ ano Hybrid material with $10 \%$ bleaching agent.

In the present study, although there were reduction in bond strength of the groups treated with Carbamide peroxide at 10 and $21 \%$ for both Nano Hybrid material and $\mathrm{Nano} \mathrm{Hybrid}$ material restorative materials when compared with the control groups that were stored in artificial saliva, it were statistically in- significant.

The effects of whitening agents on hard dental tissues are tooth sensitivity during bleaching is the most common side effect with the degree of sensitivity varying between patients. Sensitivity, if it occurs during treatment is usually not permanent. Tooth sensitivity, if present, normally persists for up to four days after the cessation of bleaching. Sensitivity can be decreased by decreasing the amount exposure to the bleaching solution per day. Research had shown that toothpastes containing potassium nitrate used for 2 weeks prior to teeth whitening helps to decrease the sensitivity during bleaching. ${ }^{5}$

It had been concluded that the use of dentistmonitored, at-home tooth whitening gels containing 10\% Carbamide Peroxide carries no carcinogenic risk and does not cause irreversible damage to enamel. ${ }^{5}$ Gingival irritation is another possible side 
effect that occurs when the bleaching solution comes in contact with the gums. ${ }^{5}$ Gastro-intestinal irritation can also occur, mainly with at-home bleaching systems that are worn over night. ${ }^{5}$

Thomas Attin et al (2004) evaluated in some scanning electron microscopic studies and profilometric analysis, it was shown that $10-16 \%$ Carbamide Peroxide bleaching gels (i.e. 3.6-5.76\% Hydrogen Peroxide) may lead to a slight, but statistically significant increase in surface roughness and amount of porosities of Microfilled and Hybrid Composite resins. ${ }^{6}$

Thomas Attin et al (2004) said that the overwhelming majority of studies utilizing $25-35 \%$ Hydrogen Peroxide uniformly showed that both shear bond strength and tensile bond strength of all Composite restorative materials tested were significantly reduced when Composite application (including acid-etching pre-treatment) was performed immediately, i.e. within 1 day, after completion of bleaching regime. ${ }^{6}$

In the present study the Shear bond strength of Nano Hybrid Compositematerial were better than the Nano Composite material.

\section{CONCLUSION:}

Following conclusions were drawn from the study: (1) There was a significant reduction in the Shear bond strength of restorative materials observed after exposure to Carbamide Peroxide agents under a clinically simulated bleaching regimen. This had clinical implications on posttreatment out comes Carbamide peroxide bleaching gel at concentrations $10 \%$ and $21 \%$ caused a reduction in hardness of Composite. (2) In general the Shear bond strength of Nano Hybrid material was better than the Nano Composite.

Further in-vivo studies are needed to evaluate the other associated effects of bleaching on restorations such as the surface roughness, micro leakage and color changes in tooth colored restorative materials which can significantly enhance the findings of the present study.

\section{REFERENCES:}

1. Sung EC, Chan M, Mito B R, Caputo AA. Effect of carbamide peroxide bleaching on the shear bond strength of composite to dental bonding agent enhanced enamel. J Prosth Dent 1999; 82,595-599.

2. Valeria V Gordan, Amer Abu-Hanna, Ivar A Mjor. Esthetic Dentistry in North American Dental Schools. J Can Dent Ass 2004; 70(4):230-223.

3. Cavalli V, Arrais CAG, Giannini M, Ambrosano MB. Highconcentrated carbamide peroxide bleaching agent's effects on enamel surface. J Oral Rehab 2004; 31:155-159.

4. Prabhakar R, Suzan Sahana, Mahantesh T, Vishwas TD. Effects of different concentrations of bleaching agent on the micro hardness and shear bond strength of restorative materials - An in vitro study. J Dent Oral Hyg 2010; 2(1):714.

5. Kinjal Shah, Lotika Beri, Indrajeet Baad. Bleaching of Teeth: The Yellow And White of It- Part I. Int J Dent Prac Med Sci 2012;1(1).

6. Thomas Attin, Christian Hannig, Annette Wieg. Rengin Attin. Effect of bleaching on restorative materials and restorations-a systematic review. Dent Mat 2004; 20: 852:861.

\section{Gain quick access to our journal online View our journal at www.nacd.in}

